\title{
A COMPARATIVE STUDY OF HYSTEROSCOPIC MORCELLATION OR RESECTION OF UTERINE POLYPS
}

\author{
Aleksandar D. Lyubenov, \\ Slavcho T. Tomov', \\ Desislava K. Kiprova, \\ Grigor A. Gorchev, \\ Kameliya T. Tsvetanova ${ }^{2}$ \\ Department of Obstetrics and \\ Gynecology, \\ Saint Marina University Hospital - \\ Pleven, \\ Bulgaria \\ ${ }^{1}$ Department of Midwifery, \\ Medical University - Pleven, \\ Bulgaria \\ ${ }^{2}$ Department of Anaesthesiology and \\ Resuscitation, \\ Medical University - Pleven, \\ Bulgaria
}

Corresponding Author:

Aleksandar D. Lyubenov

Saint Marina University Hospital - Pleven,

West Zone Industrilna,

Bulgarian Aviation Str.

Pleven, 5800

Bulgaria

e-mail: aleksandar_ljubenov@yahoo.co.uk

Received: May 26, 2019

Revision received: June 19, 2019

Accepted: July 30, 2019

\section{Summary}

The aim of the study was to analyse the intraoperative parameters of hysteroscopic morcellation (HM) and conventional resectoscopy in the treatment of uterine polyps (UP). A total of 177 patients with ultrasound imaging of UP were included in a prospective study from February 2015 to February 2017. Out of them, 98 (55.4\%) underwent HM and 79 (44.6\%) had hysteroscopic resection (HR). We analyzed the following intraoperative parameters: total duration of the procedure, total operating time, time for dilation, actual operating time for $\mathrm{HM} / \mathrm{HR}$, the total amount of fluid distension media and fluid deficit. The mean operating time, measured as a total duration of the procedure, total operating time and actual operating time, was significantly shorter in the HM group, as compared to HR group, 8.27 and 19.48 minutes $(\min )-p<0.001,6.15$ and $16.33 \min (p<0.001)$, 3.28 and $11.70 \mathrm{~min}(\mathrm{p}<0.001)$, respectively. The total amount of fluid distension media was trustworthy lower in the HM group compared to HR, $446.02 \mathrm{ml}$ and 2225.57 millilitres $(\mathrm{ml})-\mathrm{p}<0.001$, respectively, as well as for the fluid deficit parameter - respectively $83.78 \mathrm{ml}$ and $413.48 \mathrm{ml}(\mathrm{p}<0.001)$. This warrants the assumption that HM is an effective alternative to conventional resectoscopy for removal of UP with a favorable perioperative outcome.

Key words: hysteroscopic morcellation, hysteroscopic resection, uterine polyp

\section{Introduction}

The clinical manifestation of endometrial polyps is associated with symptoms such as postmenopausal bleeding, menorrhagia, intermenstrual bleeding and infertility. With the advent of high-resolution ultrasound and the possibility of diagnostic hysteroscopy, it has become clear that abnormal uterine bleeding is associated with endometrial polyps more often than previously thought. The presence of endometrial polyps ranges from $7.8 \%$ to $34.9 \%$, depending on the studied population [1].

Hysteroscopy is a technique that improves both diagnostic precision and effectiveness in the treatment of some intrauterine pathologies. Use of hysteroscopy in abnormal uterine bleeding today has almost completely replaced the blind curettage, due to the possibility of accurate visualization of the pathological finding that has led to the clinical manifestation. Because of its safety and effectiveness, operative hysteroscopy 
has become a benchmark in gynaecological practice [2]. Hysteroscopic resection (HR) with high-frequency electric current is a "gold standard" for removal of uterine polyps (UP). In recent years, a new device called hysteroscopic morcellator has become widely available and applicable in gynaecological practice. It uses a mechanical cutting force, through which it crushes the intrauterine formation in small fragments and simultaneously, through suction, removes them from the uterine cavity. That is why the device is considered to be effective and at the same time, a safe method for removal of intrauterine lesions [3, 4]. Besides, there are many announcements about the ease of HM-use, which gives us a reason to accept that it can be an alternative to HR, both in experienced and inexperienced hands [5]. Our study and the need for our results were provoked by the fact that the studies conducted so far are different in design and range, and with ambiguous conclusions.

To compare both surgical techniques (HR and HM) in treatment of UP by analyzing the main intraoperative parameters.

\section{Materials and Methods}

We included a total of 177 patients with ultrasound data of UP in a prospective study for the period from February 2015 to February 2017. Of them, 98 (55.4\%) underwent HM and $79(44.6 \%)-\mathrm{HR}$.

According to the size of the polyp, the distribution was as follows: up to $1 \mathrm{~cm}-70$ $(39.5 \%)$ cases [40 (22.5\%) - HM, $30(16.9 \%)$ - HR]; $1-2 \mathrm{~cm}-92(51.9 \%)$ cases [49 (27.6\%) HM, $43(24.3 \%)-\mathrm{HR}]$; over $2 \mathrm{~cm}-18(10.1 \%)$ cases $[10(5.6 \%)-\mathrm{HM}, 8(4.5 \%)-\mathrm{HR}]-$ Table 1.

Table 1. Distribution of the patients according to the size of the polyp

\begin{tabular}{llll}
\hline Size of the polyp & $\mathbf{n}$ & $\mathbf{\%}$ & Sp \\
\hline Up to $1 \mathrm{~cm}$ & 70 & 39.5 & 2.2 \\
$1-2 \mathrm{~cm}$ & 92 & 51.9 & 2.4 \\
Over $2 \mathrm{~cm}$ & 18 & 10.1 & 1.2 \\
Total & 177 & 100.0 & \\
\hline
\end{tabular}

HRs were performed with a Karl Storz ${ }^{\circledR}$ monopolar resectoscope, with a $4 \mathrm{~mm}$ telescope and a $0.8 \mathrm{~mm}$ cutting loop (Figure 1), and the morcellations - with the IBS ${ }^{\circledR}$ system, Karl Storz ${ }^{\circledR}$, with a $4 \mathrm{~mm}$ diameter concave double serrated shaver blade with oval cutting window or with a $4 \mathrm{~mm}$ diameter double serrated blade with rectangular cutting window (Figure 2).

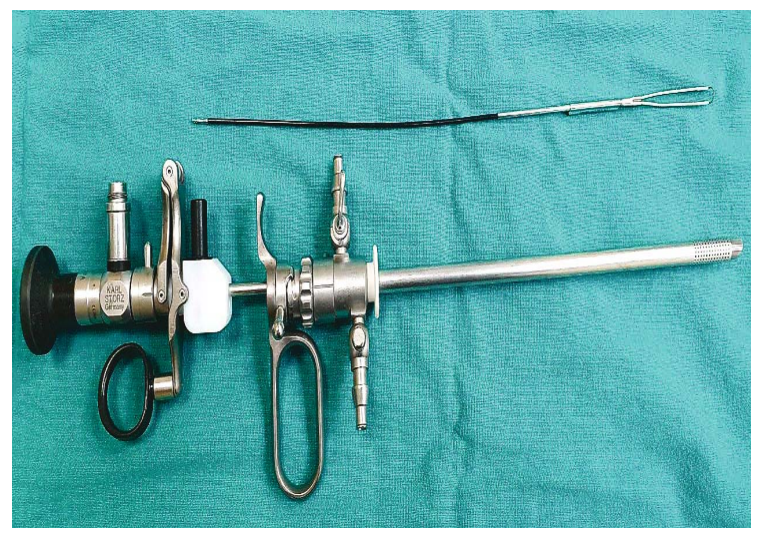

Figure 1. Karl Storz ${ }^{\circledR}$ monopolar resectoscope

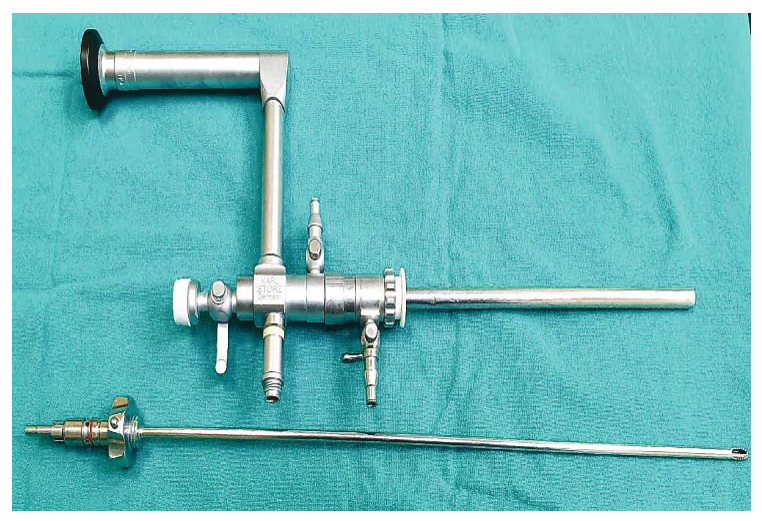

Figure 2. Intrauterine Bigatti shaver - IBS ${ }^{\circledR}$ system, Karl Storz ${ }^{\circledR}$

The patients in the main group, who underwent operative hysteroscopy, were under 50 years, with a largest relative share in the agegroup 40-49, followed by the group 30-39, while the lowest relative share was in the group up to 30 years (Figure 3 ).

= Younger than $30=30-39=40-49=50-60=$ Older than 60

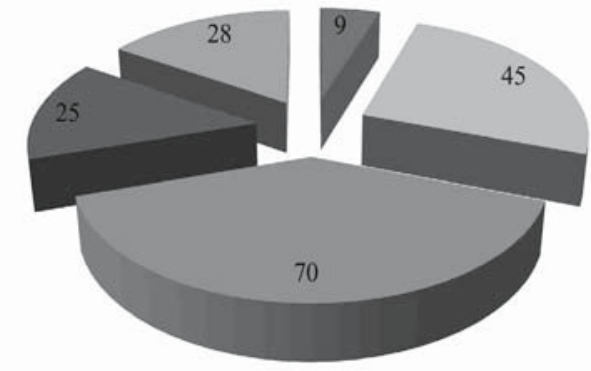

Figure 3. Age distribution of the patients (number of patients) 
We analyzed intraoperative parameters, as follows: total duration of the procedure, defined as time in minutes ( $\mathrm{min}$ ) from the beginning of anesthesia introduction until the end of the anesthesia; total operating time - the time from the beginning of the dilation to the end of the intervention ( $\mathrm{min}$ ); dilation time (min); actual operating time for morcellation/resection (min); total fluid amount (in milliliters) used during the procedure and fluid deficit (in milliliters), defined as the difference between the amount of fluid distension media used during the procedure, and the available fluid amount reported after its end. The non-parametric tests of Kruskal-Wallis, Mann-Whitney, Kolmogorov-Smirnov and
Shapiro-Wilk, Student's t-test and the one-way analysis of variance (ANOVA) were applied for statistical analysis.

\section{Results}

The mean operating time, assessed as "total duration of the procedure", "total operating time" and "actual operating time", was significantly shorter in the HM group compared to HR group, respectively 8.27 versus 19.48 $\min (\mathrm{p}<0.001) ; 6.15$ vs. $16.33 \min (\mathrm{p}<0.001)$ and 3.28 vs. $11.70 \mathrm{~min}(\mathrm{p}<0.001)$. There was no significant difference in dilation time between the two operative procedures -1.37 vs $1.54 \mathrm{~min}$

Table 2. Comparative analysis of the intraoperative parameters for both operative procedures, regardless of the size of the polyp

\begin{tabular}{llllll}
\hline Parameter & HM & \multicolumn{3}{c}{ HR } & P(values) \\
& $\bar{X}$ & SD & $\bar{X}$ & SD & \\
\hline 1. Total duration of the procedure (min) & 8.27 & 2.67 & 19.48 & 6.74 & $\mathrm{P}<0.001$ \\
2. Total operating time (min) & 6.15 & 2.16 & 16.33 & 6.25 & $\mathrm{P}<0.001$ \\
3. Actual operating time (min) & 3.28 & 1.86 & 11.70 & 5.48 & $\mathrm{P}<0.001$ \\
4. Time for dilation (min) & 1.37 & 0.53 & 1.54 & 0.57 & $\mathrm{P}>0.05$ \\
5. Total amount of fluid distension media (ml) & 446.02 & 183.41 & 2225.57 & 1217.19 & $\mathrm{P}<0.001$ \\
6. Fluid deficit (ml) & 83.78 & 35.48 & 413.48 & 208.91 & $\mathrm{P}<0.001$ \\
\hline
\end{tabular}

Table 3. Comparative analysis of the intraoperative parameters according to size of the polyps; the same letters on the vertical lines mean no significant difference, the different - the presence of one $(\mathrm{p}<0.05)$

\begin{tabular}{|c|c|c|c|c|c|c|c|c|}
\hline \multirow[t]{2}{*}{ Parameter } & \multirow[t]{2}{*}{ Size of the polyp } & \multirow[t]{2}{*}{ Cases (n) } & \multicolumn{2}{|l|}{ HM } & \multirow{2}{*}{$\begin{array}{l}\text { Cases } \\
\text { (n) }\end{array}$} & \multicolumn{2}{|l|}{ HR } & \multirow[t]{2}{*}{$P$ (values) } \\
\hline & & & $\bar{X}$ & SD & & $\bar{X}$ & SD & \\
\hline \multirow[t]{3}{*}{ Fluid amount (ml) } & Up to $1 \mathrm{~cm}$ & 40 & 294.88 & 100.94 & 30 & 1237.00 & 714.04 & $<0.001$ \\
\hline & $1-2 \mathrm{~cm}$ & 49 & 507.96 & 131.07 & 43 & 2441.16 & 706.46 & $<0.001$ \\
\hline & Over $2 \mathrm{~cm}$ & 10 & 742.5 & 83.17 & 8 & 4531.25 & 1078.85 & $<0.001$ \\
\hline \multirow[t]{3}{*}{ Fluid deficit (ml) } & Up to $1 \mathrm{~cm}$ & 40 & 56.50 & 25.25 & 30 & 271.67 & 156.70 & $<0.001$ \\
\hline & $1-2 \mathrm{~cm}$ & 49 & 98.47 & 29.34 & 43 & 446.28 & 159.50 & $<0.001$ \\
\hline & Over $2 \mathrm{~cm}$ & 10 & 117.50 & 24.41 & 8 & 733.75 & 168.01 & $<0.001$ \\
\hline \multirow{3}{*}{$\begin{array}{l}\text { Total operating time } \\
\text { (min) }\end{array}$} & $\mathrm{Up}$ to $1 \mathrm{~cm}$ & 40 & 4.75 & 1.60 & 30 & 11.77 & 3.78 & $<0.001$ \\
\hline & $1-2 \mathrm{~cm}$ & 49 & 6.76 & 1.94 & 43 & 17.09 & 4.15 & $<0.001$ \\
\hline & Over $2 \mathrm{~cm}$ & 10 & 8.60 & 1.51 & 8 & 27.88 & 6.08 & $<0.001$ \\
\hline \multirow{3}{*}{$\begin{array}{l}\text { Time for dilation } \\
(\mathrm{min})\end{array}$} & Up to $1 \mathrm{~cm}$ & 40 & 1.40 & 0.55 & 30 & 1.63 & 0.56 & $>0.05$ \\
\hline & $1-2 \mathrm{~cm}$ & 49 & 1.33 & 0.52 & 43 & 1.51 & 0.59 & $>0.05$ \\
\hline & Over $2 \mathrm{~cm}$ & 10 & 1.40 & 0.52 & 8 & $1.50^{\mathrm{a}}$ & 0.76 & $>0.05$ \\
\hline \multirow{3}{*}{$\begin{array}{l}\text { Actual operating } \\
\text { time (min) }\end{array}$} & Up to $1 \mathrm{~cm}$ & 40 & 1.98 & 1.12 & 30 & 7.83 & 3.35 & $<0.001$ \\
\hline & $1-2 \mathrm{~cm}$ & 49 & 3.80 & 1.68 & 43 & 12.12 & 3.33 & $<0.001$ \\
\hline & Over $2 \mathrm{~cm}$ & 10 & 5.70 & 1.34 & 8 & 22.63 & 5.24 & $<0.001$ \\
\hline \multirow{3}{*}{$\begin{array}{l}\text { Total duration of the } \\
\text { procedure (min) }\end{array}$} & $\mathrm{Up}$ to $1 \mathrm{~cm}$ & 40 & 6.63 & 2.24 & 30 & 14.83 & 4.22 & $<0.001$ \\
\hline & $1-2 \mathrm{~cm}$ & 49 & 8.96 & 2.32 & 43 & 20.19 & 4.33 & $<0.001$ \\
\hline & Over $2 \mathrm{~cm}$ & 10 & 11.30 & 1.34 & 8 & 31.88 & 7.55 & $<0.001$ \\
\hline
\end{tabular}


( $>0.05$ ). The total amount of fluid distension media was statistically trustworthy lower in the HM group compared to HR, respectively 446.02 $\mathrm{ml}$ and $2225.57 \mathrm{ml}(\mathrm{p}<0.001)$. The results were similar for the parameter "fluid deficit", resp. $83.78 \mathrm{ml}$ for HM group and $413.48 \mathrm{ml}$ for the group of HR $(p<0.001)$. Table 2 and Table 3 show the results for the parameters analyzed according to the size of the polyps.

Statistically reliable conclusions can be drawn for each of the polyp sizes. The HR groups in all three sizes of polyps were with significantly higher mean values for each of the parameters without dilation time.

\section{Discussion}

After the invention of the "Lichtleiter" or "Light Conductor" (Bozzini, 1807), the first successful attempt for hysteroscopy was reported by Pantaleoni in 1869. While examining the uterine cavity of a 60 -year-old woman with postmenopausal bleeding, he found an endometrial polyp, which he cauterized with silver nitrate. The procedure became not only the first diagnostic hysteroscopy, but the first known case of intrauterine surgery as well [6].

Operative hysteroscopy is a widely used procedure in various types of intrauterine pathology. The main techniques used in operative hysteroscopy are HM and HR. The resectoscope is a well-known instrument, which is routinely used for a variety of intrauterine manipulations. Since 2005, three generations of intrauterine mechanical morcellators have been invented - TRUCLEAR ${ }^{\mathrm{TM}}$, MyoSure ${ }^{\circledR}$, and $\mathrm{IBS}^{\circledR}$. They all rely on mechanical suction-based energy and a rotating tubular cutting system instead of high-frequency electric energy used by the resectoscopes for removal of abnormal intrauterine tissues [7]. To date, not many studies comparing both hysteroscopic techniques for removal of UP have been published [8]. A study of Hamerlynck et al. compared HM and HR in 84 women with endometrial polyps $\geq 1$ $\mathrm{cm}$. The mean operating time they reported was $4.0 \mathrm{~min}$ (range: $2.5-7.1$ ) for $\mathrm{HM}$ and $6.0 \mathrm{~min}$ (range: 3.8-11.7) for HM, which means 38\% reduction of operating time in the HM group. The total duration of the procedure (installation time+operating time), presented in their comparison, was 9.5 min for $\mathrm{HM}$ and $12.2 \mathrm{~min}$ for HR. They also reported a uterine perforation in 3 cases of HR and 1 case of HM [8].

Similar results were reported in another trial, which included 121 women and compared both hysteroscopic techniques for removal of UP. The mean operating time for HM was 5.28 min, and for HR - 10.12 min. Complete polyps removal was achieved in 61 out of 62 women (98\%) in the HM group, compared to 49 out of 59 women $(83 \%)$ in the HR group. The authors also presented the assessment of pain: 35.9 for HM and 52.0 for HR [9]. The main conclusions that can be drawn are that HM is faster, less painful and more acceptable to women procedure, which more often achieves complete removal of the endometrial polyp, as compared to HR. Also, one retrospective cohort study on 311 patients (139 HM and $172 \mathrm{HR}$ ) observed the recurrent abnormal uterine bleeding after hysteroscopic polypectomy and reported that $\mathrm{HM}$ was associated with lower recurrence of endometrial polyps [10]. This is probably related to their more complete removal.

In our study, complete removal of intrauterine pathology was achieved in all cases, in both of the HM and HR group. Regarding the intraoperative and postoperative complications, we observed none in both groups. No patient underwent a hysteroscopic procedure for abnormal uterine bleeding or ultrasound evidence of polyp for a period of one year.

Our experience fully supports the statements related to the benefits of HM in the treatment of UP, namely better visual control, the safety of saline solution use and mechanical cutting energy. The use of $0.9 \%$ saline solution reduces the risk of complications associated with a fluid deficit. High-frequency current is not used, which reduces the risk of uterine perforation. Providing a clear view of the working area allows less time for work. Aspiration of the tissue fragments by the HM ensures a clear view as well as the preservation of tissue for histological examination. These fragments are entirely maintained without any signs of electrical damage (Figure 4).

Unlike HR, HM does no damage to the surroundings of the lesion, which has to be removed.Furthermore, duringHM, nogas bubbles arise, which may defeat the visual procedure 


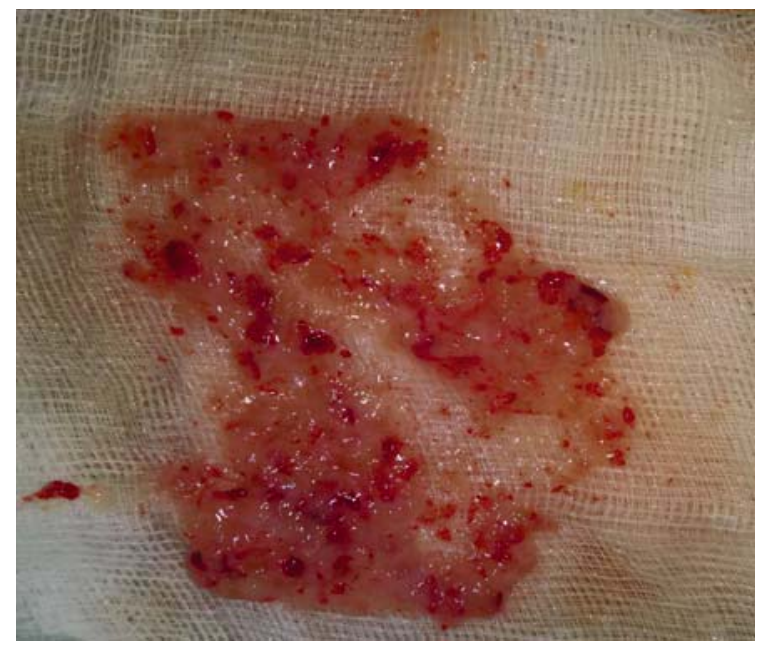

Figure 4. Morcellated polyps fragments - our material

control [5]. HM allows the use of hysteroscopes with a smaller diameter. We find HM as a very suitable surgical method for nulliparas due to the less cervical dilation and single insertion of the hysteroscope, which protects against cervical lacerations. In conventional resectoscopy, tissue fragments can block the hysteroscopic view, and they need to be removed one by one. Thereby they make repeated "in and out" movements necessary, leading not only to possible specimen loss but also to potential uterine damage [5]. The study results correspond with those of the above-cited authors regarding the investigated parameters "operating time" and "total amount of fluid distension media". The possibility of simultaneous aspiration of the morcellated fragments significantly reduces the operating time as well as the total amount of fluid distension media used. This is best demonstrated in the treatment of large UPs and multiple polyposes. Operating time for both HM and HR varies widely and depends not only on the size, number and location of the pathological finding, but also on the surgeon's experience. Operating time, as well as the other parameters, increases significantly in both groups with an increase in the size of the pathological intrauterine findings, except the parameter "time for dilation", as shown in Table 3.

As regards the learning curve, the benefits are again for HM, which demonstrates a higher level of autonomy and confidence during the procedure [11].

HM notably decreases the total duration of polypectomy and hysteroscopy when performed both by experienced staff and by staff in training, leading to higher success rates without complications [12].

There is still no consensus on what kind of operative hysteroscopy should be performed on a patient who has evidence of intrauterine surgery. Compared to HR, HM is a faster and easier procedure with less fluid deficit related complications. Besides, reduced costs and efficiency improvements are noted [7]. Therefore, it can be expected that this technique for removal of UP can lead to fewer complications, compared to conventional resectoscopy, being at the same time more effective and with a shorter learning curve [13].

\section{Conclusions}

$\mathrm{HM}$ is an efficient and safe alternative to conventional resectoscopy for removal of UP. Our study shows that this technique offers a chance for shorter operating time and, at the same time, higher safety. However, for its successful confirmation, further research is needed, both for results validation and for data, concerning the learning curve and the pain experienced by patients.

\section{Acknowledgements}

This article was not part of a project and has received no financial support. The authors declare that there are no conflicts of interest.

\section{References}

1. Salim S, Won H, Nesbitt-Hawes E, Campbell $\mathrm{N}$, Abbott J. Diagnosis and management of endometrial polyps: a critical review of literature. J Minim Invasive Gynaecol. 2011;18(5):569-81.

2. Tarneja P, Duggal BS. Hysteroscopy: Past, present and future. Med J, Armed Forces India. 2002;58(4):293-4.

3. Lukes AS. MyoSure ${ }^{\circledR}$ Tissue Removal System - Comparative Sedation Study in an office setting. J Minim Invasive Gynecol. 2010;17(6 suppl):S67.

4. Miller CE, Glazerman L, Roy K, Lukes A. Clinical evaluation of a new hysteroscopic morcellator - retrospective case review. J Med. 2009;2(3):163-6.

5. Hamerlynck TW, Dietz V, Schoot BC. Clinical implementation of the hysteroscopic morcellator 
for removal of intrauterine myomas and polyps. A retrospective descriptive study. Gynecol Surg. 2011;8(2):193-6.

6. Marlow JL. Media and delivery systems. Obstet Gynecol Clin North Am. 1995; 22(3):409-22.

7. Cohen S, Greenberg JA. Hysteroscopic morcellation for treating intrauterine pathology. Rev Obstet Gynecol. 2011;4(2):73-80.

8. Hamerlynck TW, Schoot BC, van Vliet HA, Weyers S. Removal of endometrial polyps: hysteroscopic morcellation versus bipolar resectoscopy, a randomized trial. J Minim Invasive Gynecol. 2015;22(7):1237-43.

9. Smith PP, Middleton LJ, Connor M, Clark TJ. Hysteroscopic morcellation compared with electrical resection of endometrial polyps: a randomized controlled trial. Obstet Gynecol. 2014;123(4):745-51.

10. AlHilli MM, Nixon KE, Hopkins MR, Weaver AL, Laughlin-Tommaso SK, Famuyide AO. Long-term outcomes after intrauterine morcellation vs. hysteroscopic resection of endometrial polyps. J Minim Invasive Gynecol. 2013;20(2):215-21.
11. Pampalona JR, Bastos MD, Moreno GM, Pust AB, Montesdeoca GE, Guerra Garcia A, et al. A comparison of hysteroscopic mechanical tissue removal with bipolar electrical resection for the management of endometrial polyps in an ambulatory care setting: preliminary results. J Minim Invasive Gynecol. 2015;22(3):439-45.

12. Rovira Pampalona J, Degollada Bastos M, Mancebo Moreno G, Ratia Garcia E, Buron Pust A, Mateu Pruñonosa JC, et al. Outpatient Hysteroscopic Polypectomy: Bipolar Energy System (Versapoint ${ }^{\circledR}$ ) versus Mechanical Energy System (TRUCLEAR System®) preliminary results. Gynecol Obstet Invest. 2015;80(1):3-9.

13. Emanuel MH, Wamsteker K. The intrauterine morcellator: a new hysteroscopic operating technique to remove intrauterine polyps and myomas. J Min Invasive Gynecol. 2005;12(1):62-6. 